\title{
Histories obtained by two-stage questionnaire with automated transcript in specialist gynaecological practice
}

\author{
D W ROBINSON, G L WALMSLEY, JANE C HORROCKS, PAULINE MILSON, D M JENKINS, \\ F T DE DOMBAL, J S SCOTT
}

British Medical fournal, 1975, 4, 510-513

\section{Summary}

A two-stage questionnaire which the patient completes at home has been developed for use by gynaecological outpatients. The first stage (root) identifies the patient's problem and obtains general background information. The second stage (branch) deals with the presenting problem in depth. The system has proved highly acceptable to patients.

At the clinic a non-medical assistant uses a programmed typewriter to transcribe the data into a typewritten history which is handed to the doctor before he examines the patient. The transcript compares favourably with the conventional hand-written history in content, ease of assimilation, and cost. While the questionnaire itself is an excellent means of collecting information it becomes an efficient means of transmitting information to the clinician only when combined with the transcript facility. There is no storage of confidential information and no scope for unethical disclosure.

\section{Introduction}

A concise accurate history is vital in medical practice. In gynaecology numerical items such as the date of the last menstrual period, the length of the menstrual cycle, and details of pregnancies present special problems. Patients are slow to recall these details on direct questioning and their answers may be inaccurate. ${ }^{1}$ Errors or omissions can lead to mistakes in diagnosis and management. In our clinics one consultant has to see up to 20 new patients, teach students, and supervise about 50 revisits. History-taking falls to junior doctors whose capabilities vary and the encounter may be embarrassing for certain patients. Pressures of time lead to deficiencies and may result in frustration and tensions for both doctor and patient.

We thought this state of affairs might be improved if the basic

Department of Obstetrics and Gynaecology, University of Leeds Leeds LS2 9NG

D W ROBINSON, MSC, MRCOG, research fellow

PAULINE MILSON, medical secretary

D M JENKINS, MD, MRCOG, senior lecturer and honorary consultant

J S SCOTT, MD, FRCOG, professor of obstetrics and gynaecology

University Department of Surgery, General Infirmary, Leeds LS 3EX

G L WALMSLEY, MB, CHB, research assistant

JANE C HORROCKS, computer programmer and physician's assistant F T DE DOMBAL, MD, FRCS, reader in clinical information science information was recorded at leisure in the patient's home using a questionnaire. She could then consult calendars and relatives to check details. The first basic questionnaire, which covered only such facts as age and menstrual history, was used in the professorial unit at the Hospital for Women at Leeds in 1968. It was well received and proved reliable in practice. With this satisfactory experience the scheme was extended to cover the complete history required for outpatient consultation. We report here on the system and an analysis of its operation.

\section{The questionnaire}

\section{DEVELOPMENT}

A list of 24 categories of presenting problems was established which covered virtually all conditions in gynaecology (table I). These were framed as questions in lay language and formed a primary or root questionnaire when combined with an extended form of the basic questionnaire covering health background, marital status, and, where appropriate, attitudes to pregnancy and contraceptive practice. For each problem a secondary or branch questionnaire was devised. A small group of clinicians decided what information was needed in each clinical situation and framed appropriately worded questions. Most required a yes/no answer, but for a few information had to be written in. If a particular answer made subsidiary questions unnecessary a bypass operated and the patient was led to the next question. On average branch questionnaires listed 12 questions (range 8-24), but the bypass procedure often reduced the number to be answered.

The gynaecological history may involve personal and sexual questions and we hesitated initially to include these in questionnaires. When the general acceptability of the system had been established, however, more intimate questions were gradually introduced. Phrasing was given repeated consideration and patients were asked to point out ambiguities or difficulties. It transpired that many standard questions were subject to serious misinterpretation. In their current form the questions are an amalgam of those used by different clinicians, refired in the light of patient response. The two-stage questionnaire has been in use for three years. Only a proportion of new patients have been sent questionnaires in order to allow careful assessment of any problems.

\section{PRODUCTION OF THE TRANSCRIPT}

It was soon apparent that while the questionnaire was an efficient and acceptable means of acquiring information its format made assimilation of the answers difficult even with use. A system was therefore devised to produce a typewritten transcript on a semiautomated basis. By linking an electric typewriter to a programmable desk-top calculator (Wang $700 \mathrm{C}$ ) it became possible to generate typewritten answers, which otherwise would have required up to 50 typing pressures, by a single touch of a key. After decisions on what answers were to be included the sequence was programmed by one of us $(\mathrm{JCH})$.

The answers were rephrased in medical language. Thus the affirmative answer to "Do you wet yourself on coughing or sneezing?" 
TABLE I-Problems listed in root questionnaire. These are translated to lay language for presentation to patient (see fig 1)

Primary amenorrhoea
Secondary amenorrhoea
Abnormal periods/vaginal bleeding
Dysmenorrhoea
Post menopausal bleeding
Vaginal bleeding before puberty
Urinary incontinence
Other urinary problems
Sensation of prolapse
Coital problems
Primary Infertility
Secondary Infertility
Recurrent abortion

\section{Abdominal pain}

Abdominal swelling

Vulval pain

Vulval swelling

Vaginal discharge

Pruritus

Request for contraception

Request for sterilisation

Hirsutism

Menopausal problems

became, in transcript, "has stress incontinence." We distinguished between the few answers whose importance was such that their inclusion was necessary irrespective of response-for example, in amenorrhoea, "hormones produced withdrawal bleeding" or "hormones did not produce withdrawal bleeding"-and the majority, which needed to appear only when in the affirmative-for example, "has noticed deepening of the voice." If there had been no change in the voice nothing appeared in the transcript but the clinician knew the question had been put and answered in the negative. Occasionally the negative answer was the important alternative-for example, "does not achieve orgasm"-in which case this only was printed.

\section{THE SYSTEM IN PRACTICE}

The office staff send the patient her appointment and include a root questionnaire and the branch questionnaire relevant to the problem(s) indicated in the general practitioner's referral letter. If the patient has no symptoms but is referred because of a finding at a "well woman" examination such as atypical cervical cytology she is sent a root questionnaire but no branch section. The forms do not carry the patient's name and there is no provision for the patient to enter it so that if they go astray they cannot be identified with the individual. An accompanying letter indicates that completing the questionnaire beforehand can save time at the clinic.

In the root questionnaire the patient can confirm the reason for referral and may indicate additional problems. She records menstrual, marital, contraceptive, and health information as appropriate. In the branch questionnaire she amplifies details of her problem. The patient brings the questionnaire to the clinic and an assistant, who need not be a doctor, checks that all sections are completed and helps with minor difficulties in comprehension. If a problem not indicated in the referring letter is mentioned the patient is given a further branch questionnaire to complete. While the patient is changing for examination the assistant can make the transcript. The consultant, as he meets the patient, has at hand a concise typed statement of the symptoms together with the necessary background information.

For example, if a patient confirms on the root questionnaire that her problem is "difficulty in becoming pregnant for the first time" or primary infertility (fig 1 ) then she answers the basic section, and bypasses questions on contraception and previous pregnancies. She answers the branch questionnaire as indicated in fig 2 . The assistant checks these answers and refers to the code sheet for the primary infertility transcript (fig 3). The answers made by this patient are coded as: $10-01,-02,-04$, etc, and each of these represents a preprogrammed answer. On pressing the keys in sequence the relevant phrases are selected by the calculator and printed automatically by the electric typewriter, which produces the transcript shown in fig 4 . The numerical items " 18 months," "aged 26 ," and the patient's identifying particulars are typed in manually. In this example 18 questions were answered in the branch questionnaire, and 11 items appeared in the transcript.

\section{METHODS OF EVALUATION}

Quality comparisons-To overcome the problem of achieving "blind" comparisons between hand-written conventional histories and the questionnaire transcript 25 conventional histories were taken at random and the decipherable facts were reorganised systematically and typewritten like the transcript. Each was matched with a questionnaire transcript from a patient of similar age, social class, and gynaecological problem. The pairs were submitted for comparative qualitative assessment to six gynaecologist referees who did not know which

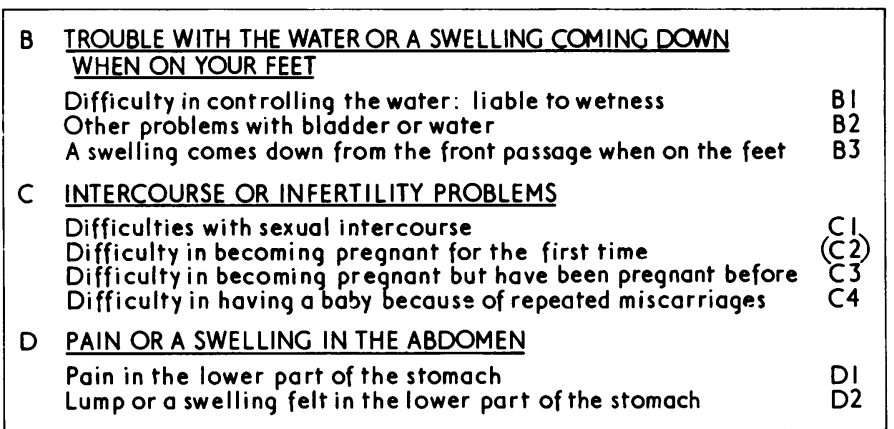

FIG 1 -Segment of root questionnaire. Patient indicates her problem by circling number on right.

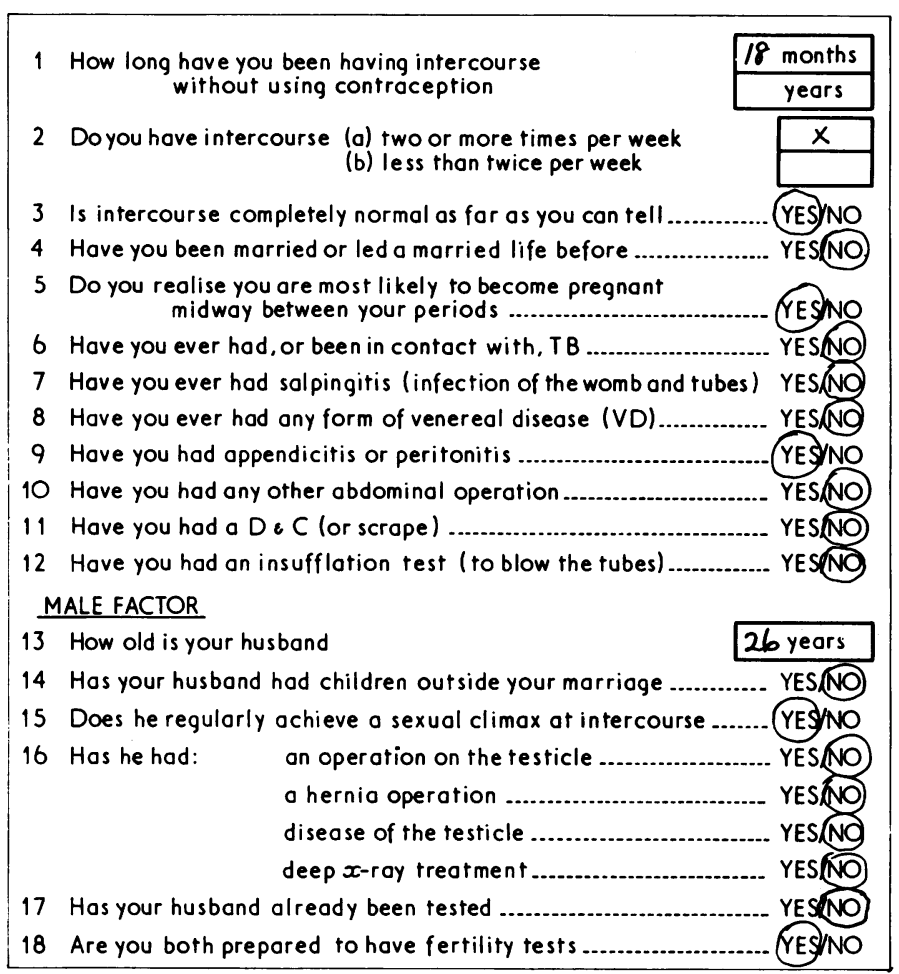

FIG 2-Branch questionnaire for primary infertility. Patient is asked to circle her answer or fill in box to the right.

\begin{tabular}{|lc|}
\hline INFORMATION & CODE \\
PRIMARY INFERTILITY & $10-\infty$ \\
Trying for & $10-01$ \\
Intercourse twice or more per week & $10-02$ \\
Intercourse less than twice per week & $10-03$ \\
Intercourse seems normal & $10-04$ \\
Intercourse does not seem normal & $10-05$ \\
Has led a married life before & $10-06$ \\
Has not led a married life before & $10-07$ \\
Knows fertile time & $10-68$ \\
\hline
\end{tabular}

FIG 3-Method of coding data for primary infertility. Codes circled correspond with patient's answers from fig 2.

were the questionnaire transcript histories. The factual data contained in both types of history were then analysed. Several key questions were identified for particular problems and conventional histories were searched to determine if they were covered.

Time and cost-Patients were asked how long they spent with the questionnaire at home. The non-medical staff time involved was 
measured and costed with the material costs of the system. Conventional histories were timed and costed. The time senior doctors took to assimilate the information was recorded for conventional histories, questionnaire transcript histories, and also for the questionnaire alone without a transcript.

Users reactions-Patients were asked their reactions and the consultants were asked to indicate their assessment of each history.

\begin{tabular}{|c|c|c|}
\hline$\frac{\text { NAME }}{\text { ADDRESS }}$ & CONSULTANT & 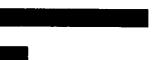 \\
\hline DOB $\quad 1.9 .48$ & DATE of ATTEND & DANCE 1.10 .74 \\
\hline RELIGION None & & \\
\hline OWN DOCTOR & REFERRED BY & $G P$ \\
\hline REASON FOR REFERRAL & LITY & \\
\hline CYCLE 3Oday & & \\
\hline MAIN PROBLEM AS STATED BY PATIENT & & \\
\hline $\begin{array}{l}\text { PRIMARY INFERTILITY } \\
\text { Trying for } 18 \text { months } \\
\text { Intercourse twice or more per week } \\
\text { Intercourse seems normal } \\
\text { Has not led a married life before } \\
\text { Knows fertile time } \\
\text { Previous appendicitis/peritonitis }\end{array}$ & & \\
\hline $\begin{aligned} \text { Husband } & \text { - aged } 26 \\
& \text { - has not been a father before } \\
& \text { - e jaculates regularly } \\
& \text { - no relevant history }\end{aligned}$ & & \\
\hline Both prepared to have tests & & \\
\hline GENERAL HEALTH BACKGROUND & & \\
\hline 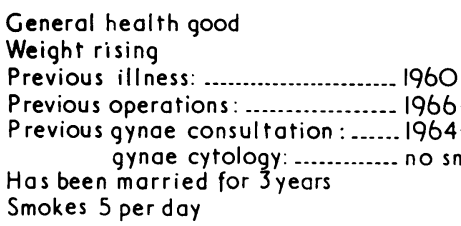 & $\begin{array}{l}\text { ndice } \\
\text { endicectomy } \\
\text { menorrhoea } \\
\text { in last } 2 \text { years }\end{array}$ & \\
\hline
\end{tabular}

FIG 4-Transcript for primary infertility as received by the clinician at consultation. Layout, spacing, and use of capital letters is predetermined by programme.

\section{Results}

This analysis covers the first 500 cases dealt with under the system. The patients were unselected, aged 15-78, and included all social classes.

Quality comparisons-On the "blind" comparison of the 25 matched pairs by independent assessors the questionnaire transcript histories were rated superior overall. Five gynaecologists rated the transcripts better in every case, but one assessor preferred the conventional histories in three cases. Assessment for specific items of information showed considerable deficiencies in conventional histories. The omissions in relation to a range of questions are shown in table II. All these items are routinely covered by the questionnaire though the negatives are not typed in the transcript.

Time and cost-The time taken by a senior house officer to take a personal interrogation history averaged 25 minutes. Patients claimed

TABLE II-Some deficiencies in conventional histories

\begin{tabular}{l|l|c}
\hline \multicolumn{1}{c|}{ Problem } & \multicolumn{1}{c}{ Specific point at issue } & $\begin{array}{c}\text { Omissions in } \\
\text { 20 Histories }\end{array}$ \\
\hline $\begin{array}{l}\text { Primary Infertility } \\
\text { Urinary incontinence } \\
\text { Secondary amenorrhoea }\end{array}$ & $\begin{array}{l}\text { Reference to male partner } \\
\text { Frequency of wetness }\end{array}$ & 10 \\
Menorrhagia & $\left\{\begin{array}{l}\text { Recent oral contraception } \\
\text { Coincident weight change }\end{array}\right.$ & 17 \\
Towels used per period & 17 \\
Dysmenorrhoea & Hormone treatment tried & 11 \\
Post menopausal bleeding & Restriction of activities & 8 \\
Prolapse & Previous treatment & 8 \\
Recent oestrogen therapy & 18 \\
Dyspareunia & Relieved by rest & 13 \\
Request for sterilisation & Associated urinary problems & 4 \\
& Frequency of coitus & 13 \\
Libido & 18 \\
Attitude of husband & 18 \\
\hline Understands permanence & \\
\hline
\end{tabular}

they took, on average, 16 minutes to complete the questionnaire at home. An Assistant of Secretarial grade can check the material and produce the transcript in 15 minutes at the clinic.

The time required to assimilate the information was recorded for two consultants using 20 of each type of history. The average for conventional histories was 1 minute 45 seconds; for the transcript histories 45 seconds. For the answered questionnaire without a transcript, however, the average time taken for assimilation was 2 minutes 20 seconds.

The Wang system for making the transcript cost $£ 3500$, or $£ 585$ a year, based on a six-year machine life plus service at $£ 250$ a year. Allowing for the assistant's salary (medical secretary grade) the annual running cost is $£ 2123$, or $£ 40.82$ a week. A work load of 100 patients a week is envisaged so that a single history would cost $40 \mathrm{p}$. The cost of a history that takes up 25 minutes of a senior house officer's time is $70 \mathrm{p}$, and, unless a doctor can take a hand-written history in 14 minutes, the transcript is therefore less expensive to prepare.

Users' reactions-No patient was hostile to the questionnaire, while $390\left(78^{\circ}{ }_{11}\right)$ found it helpful in explaining their problem. Altogether 385 patients $\left(77^{\circ}{ }_{10}\right)$ found the forms easy to complete while $29\left(6^{\circ}{ }_{10}\right)$ had some difficulty. Many important aspects are not amenable to precise measurement. Most patients who had previously experienced an interrogation history preferred to deal with personal and sexual matters in privacy at home rather than in response to direct questioning at a clinic. The questionnaire proved particularly successful with shy youngsters, the forgetful elderly, and immigrants, who were often helped by relatives. In no case did a consultant find the questionnaire transcript unsatisfactory for clinical management. The influence of the system on consultation was entirely beneficial and doctor-patient rapport improved substantially. By indicating the information required the questionnaire prepared the patient for the consultation and, the facts of the history being established, it left the consultant with time for less formal conversation and more subtle assessment of the patient. This aspect proved an unexpected advantage of the system.

\section{Discussion}

Medical questionnaires have been used for many years, particularly in the United States. ${ }^{2-6}$ Some have collected great volumes of data: 400 questions may be asked, ${ }^{6}$ which leads to "information overload," " when it becomes difficult for the clinician to abstract the important features. Some selectivity is required to achieve a workable system. Gledhill and Mathews ${ }^{*}$ in Melbourne devised a two-stage questionnaire in which secondary questions were selected from a computer file for every primary question answered in the affirmative. The computer then printed out a narrative-style history. Like others, ${ }^{9}$ they found their system gave insufficient emphasis to the important problems.

In Britain several questionnaires 101: $^{-2}$ have proved to be economical and acceptable means of collecting information from medical patients. Black ${ }^{14}$ was impressed by the two-stage approach, ${ }^{8}$ and Hall ${ }^{11}$ predicted that questionnaires with limited range but greater depth would prove valuable in the subspecialties. Our questionnaire is specialised and designed to take advantage of the British comprehensive system of primary health care. Patients are referred to "closed" specialist clinics with a letter stating their problem and the consultant is not expected to undertake a comprehensive health review. Our clinical system involves sequential progress from a presenting problem towards possible diagnoses, which are substantiated or eliminated. Card ${ }^{13}$ emphasised this aspect and commented that no doctor proceeds by collecting every possible bit of information before attempting a diagnosis. These features-patient referral with information from the primary doctor, who has the overall health responsibility, and the sequential progress towards diagnosis-make a branching questionnaire particularly appropriate to British specialist practice. Our experience indicates that it has advantages in gynaecology, as claimed by Backer. ${ }^{1.5}$

The questionnaire was designed to define progressively and amplify the presenting problems. The root section narrows the problem to one or two areas and the branch section leads towards diagnosis and management. Many gynaecological patients do not have specific conditions appearing in the Inter- 
national Classification of Diseases. Some are concerned that they are having intercourse without contraception yet are afraid of pregnancy, and the system was designed to bring such a "non-illness" to the fore. In other cases the condition is more complex, and some marital, coital, or personality problem is referred to the genital tract. Clinical acumen is required and detection is, if anything, more easily achieved with the questionnaire type of history, as incongruities and incompatibilities in answers are readily evident.

Much of the system's success depends on the care taken in presenting the information in a manner easily assimilated by the consultant. In the questionnaires the bypass procedure prevents superfluous answers being obtained. In the transcript irrelevant negatives are eliminated from the text, but the consultant has the advantage of knowing that the questions have been answered. In programming the calculator we took great care to translate the "lay" questions with their circled answers into concise "medical" statements, and by combining this with attention to layout, spacing, and the use of capital letters the important features were brought into prominence The consultants feel freer to converse informally with the patient, often gaining a better insight into her problem.

Confidentiality is a most important aspect. The questionnaires remain anonymous until handed to the assistant at the clinic. She, like medical secretaries, is bound by the same code of confidentiality as a doctor. ${ }^{16}$ The programmed calculator has no capacity to retain information about patients and simply generates answer phrases. The system, therefore, carries none of the problems of confidentiality that are associated with computers.

The fact that history-taking by questionnaire has been less than successful in some cases is probably related to the accumulation of too much detail with insufficient attention paid to transcription for ease of assimilation. Our experience is that a circumscribed questionnaire designed to obtain essential facts greatly facilitates gynaecological practice. There is a saving in medical manpower and the system has considerable teaching value for both students and postgraduates. The precise plan adopted in this investigation would require modification in other clinical circumstances, but the system is sufficiently simple and flexible to be readily adaptable. Material can be inserted or deleted according to the particular needs of the user. What is required at the outset is a clear definition of the information needed and the manner in which it is to be presented to the clinician.

GLW and JCH were aided by a grant from the MRC, which is acknowledged with gratitude. We thank our colleagues for the comparisons quoted and Dr J D Mathews for helpful comments.

\section{References}

${ }^{1}$ Chamberlain, G, and Johnstone, F D, Lancet, 1975, 1, 103.

2 Brodman, K, et al, fournal of the American Medical Association, 1949, 140 530.

${ }^{3}$ Collen, M F, et al, Archives of Internal Medicine, 1969, 123, 664.

4 Slack, W V, et al, New England fournal of Medicine, 1966, 274, 194.

5 Grossman, J H, et al, fournal of the American Medical Association, 1971, $215,1286$.

${ }^{6}$ Rockart, J F, et al, Archives of Internal Medicine, 1973, 132, 348

' Cross, H D, British Fournal of Hospital Medicine, 1974, 11, 65.

${ }^{8}$ Gledhill, V X, and Mathews, J D, British Fournal of Hospital Medicine, 1971, 6, Suppl p 16.

${ }^{9}$ Mayne, J G et al, Annals of Internal Medicine, 1972, 76, 923.

10 Anderson, J, and Day, J L, British Medical Fournal, 1968, 4, 636.

11 Hall, G H, British Medical fournal, 1972, 1, 42.

1.2 Gumpel, J M, and Mason, A M S, British Medical fournal, 1974, 2, 209.

${ }^{13}$ Card, W I, fournal of the Royal College of Physicians of London, 1970, 4, 183.

14 Black, D A K, Renal Disease, p 837. Oxford, Blackwell, 1972.

15 Backer, M H, et al, Obstetrics and Gynaecology, 1972, 40, 306.

${ }^{16}$ Horrocks, J C, and De Dombal, F T, British Medical fournal, 1975, 3, 421.
Craigshill Health Centre, Livingston, West Lothian

T A MCALLISTER, BA, MSC, senior clinical psychologist

Bangour Village Hospital, Broxburn, West Lothian

A E PHILIP, PHD, DIP CLIN PSYCHOL, principal clinical psychologist year $\left(1 "{ }^{\prime}\right.$ of the 10000 patients registered at the practice). The psychologist thus provided treatment for some patients who would otherwise have been seen by a general practitioner with neither the time nor the training to deal adequately with their problems.

\section{Introduction}

The principle of dealing with health problems in the community rather than in hospital led to the creation of the Livingston health services project, ${ }^{12}$ which has encouraged health service workers to develop new roles and relationships in order to increase the resources available for primary care and create an effective multidisciplinary team. The appointment of a clinical psychologist as a full-time member of this team was an attempt to provide general practitioners with direct access to a non-medical clinical specialist and to provide the psychologist with an opportunity to develop new areas of service. 